\title{
Study of slurry dewatering in a horizontally placed shell filtering construction
}

\author{
Maxim Tyulenev ${ }^{1 *}$, Sergey Markov ${ }^{1}$, Sergey Kravchenko ${ }^{1}$ and Stefan Vöth ${ }^{2}$ \\ ${ }^{1}$ T.F. Gorbachev Kuzbass State Technical University, 650000 Kemerovo, 28 Vesennyaya \\ st., Russian Federation \\ ${ }^{2}$ Technische Hochschule Georg Agricola (THGA), 44787, Herner Str. 45, Bochum, \\ Germany
}

\begin{abstract}
Dewatering of water-coal slurry or thickened product under conditions of operating SUEK-Kuzbass JSC enrichment plants is a promising direction of obtaining technogenic mineral resources. It should also be noted that the quality of the obtained product will be directly influenced by the quality of the initial raw materials. If the content of carbon particles is high and the average ash content of the solid phase is low, such a slurry will be of interest in terms of obtaining additional volumes of coal after dewatering. The object of this study is water-coal slurry obtained at the outlet of the radial thickener (thickened product). The subject of the research is technology of thickened product dewatering with the use of shell filter constructions. The aim of the work is to develop and substantiate parameters of low-cost technology of thickened product dewatering to ensure an increase in economic and environmental efficiency of mining operations. The idea of the work is to use the laws of mass transfer of suspended particles of water-coal slurry by filtering through specially made shell filter constructions (SFC).
\end{abstract}

\section{Introduction}

In addition to dissolved substances and rock particles, mine effluents and wastes from concentration plants stored in slurry reservoirs, radial thickeners and press filter cake contain a significant amount of fine coal slurry particles. Significant amounts of coal slurry, dewatered to conditioned moisture values, are of interest from an economic point of view as a source of profit from the potential raw material, which is, in fact, a waste of mining production [1-13]. At the same time, the parameters of this technogenic raw materials - in particular, high moisture content and, as a consequence, difficulty of loading and transportation to end users, as well as non-compliance of their requirements - do not allow to use them promptly and to the full extent.

The relevance of using waste from mining enterprises is also emphasized by the environmental component: reducing the technogenic impact on the region through integrated development of mineral resources with an increase in the wasteless component

\footnotetext{
* Corresponding author: tma.geolog@kuzstu.ru
} 
of technological processes will undoubtedly improve the difficult environmental situation in Kuzbass [14-17]. This will be expressed in reduction of pollution of surface and ground waters, atmosphere, soil, reduction of land intensity of enterprises due to reduction of the areas occupied by treatment facilities.

\section{Materials and Methods}

As a result of studying and analyzing the initial raw materials to be dewatered it was found that this raw material, that is the thickened product coming from the radial thickener, is the suspended particles of coal and rock in water with the size from 0 to $0,5 \mathrm{~mm}$ with the initial moisture (ratio of water to solid phase mass) from $180 \%$ to $131 \%$ and ash content from $40 \%$ to $48 \%$.

The instability of properties of the thickened product is due to the specifics of the production process of coal processing [18-26]. To carry out experimental work on the dewatering of thickened product, the methodology of the experiment was developed and approved [27-34]. The methodology was supposed to solve the following tasks:

- choose the material for the SFC;

- develop the construction of the SFC;

- choose a place to conduct the experiment;

- conduct a series of experiments on filling of SFC with water-coal slurry with its subsequent dewatering;

- conduct observations of the dewatering process with fixing of response levels;

- analyze obtained results;

- develop recommendations for using SFC for dewatering water-coal slurry under the conditions of SUEK-Kuzbass JSC concentration plants.

Various geosynthetic materials can be used as a material for the production of SFC.

The choice of the most optimal geosynthetic is determined by its filtration capacity (i.e. the ability to pass water and retain solids), cost and tensile strength.

Based on the above parameters, double-layer polypropylene with a density of $125 \mathrm{~g} / \mathrm{m}^{2}$ was chosen as a geosynthetic for the production of SFC. This material is strong enough to support the weight of the slurry body formed inside the SFC after dewatering and has satisfactory filtration characteristics.

Before each subsequent filling, samples were taken from different points of the SFC to determine the moisture content of the slurry body. Scheme of sampling for horizontal SFC (\#\# 1,2) and vertical SFC (\# 3) is shown on Fig. 1. 




Fig. 1. Sampling scheme for determining the moisture content of the slurry body

\section{Results}

In order to obtain the maximum amount of results, filling and dewatering of different SFCs was done differently.

SFC \#\# 1, 2 was filled 3 times with an interval of 7 days between fillings. Results of measurements of slurry moisture by sampling points are shown in Fig. 2.

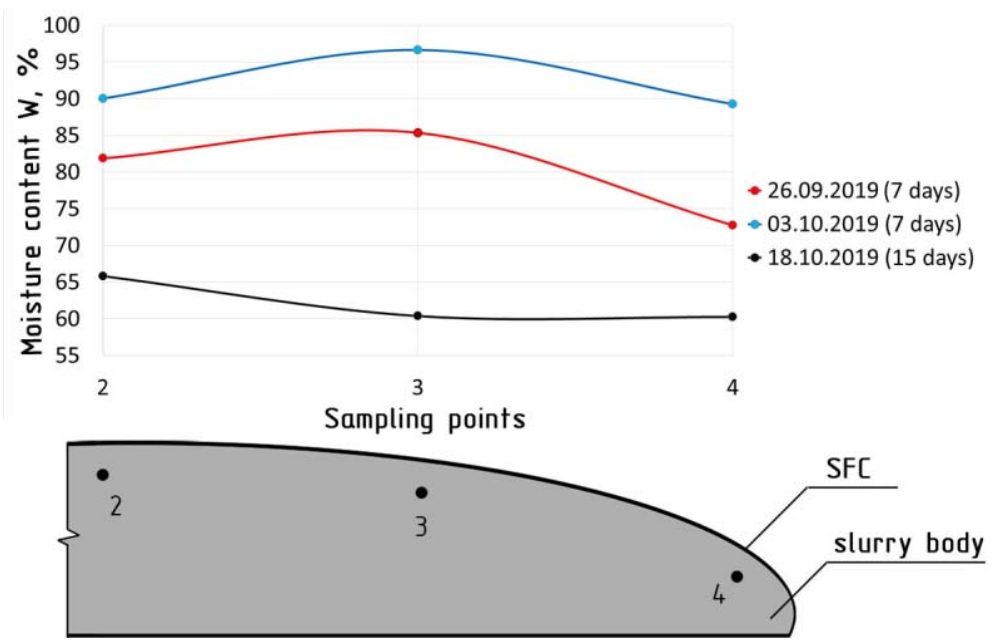

Fig. 2. Diagram of changes in the moisture content of SFC \#1 slurry over time at different sampling points (given at SFC vertical cross section).

The first filling of SFC was with pulp with moisture content of $180 \%$, the second (in 7 days) with pulp with moisture content of $167 \%$, the third (also in 7 days) with pulp with moisture content of $131 \%$. The variation of moisture content of the initial thickened product is related to the unevenness of the technological process of settling and pumping the thickened product out of the radial thickener. The output can be either a product with a low 
"solid/liquid" ratio (e.g. $131 \%$ moisture content) or a product with a high ratio $(180 \%$ moisture content).

The mentioned peculiarity of variations of parameters of the initial product didn't allow to conduct quantitative research of the process of intermediate dewatering because change of moisture content of the initial product (injected into the SFC) influenced moisture content of the slurry body already existing in the SFC differently after each new pumping cycle.

Equalization of humidity of the initial product within the framework of this study was not provided for and was not carried out.

Values of humidity in point No. 1 of sampling are not given on the graphs, since the influence of the injection hose was noticed in this point, expressed in a sharp decrease in the moisture content of the slurry body. Since the area of influence of the hose in relation to the surface area of SFC is negligibly small (less than $1 \%$ ), the value of moisture in this point is not indicative.

\section{Conclusions}

It was found that the process of dewatering, along with the shape of the SFC, is greatly influenced by the location of the SFC in space. Even with relatively small transverse dimensions of the empty shell $(0,6 \mathrm{~m})$, at its vertical filling there is a significant widening (up to $1 \mathrm{~m}$ ); in this case the process of dewatering acquires a prolonged character with preservation of the core with initial moisture in the center of the slurry body for a long time. Consequently, vertical location of SFC for the purpose of coal slurry dewatering is inexpedient.

At horizontal placing of SFC the minimum values of moisture content are observed in an edge part of SFC. Given the stretching of horizontally placed SFC at about $50-60 \%$, the most optimal cross-sectional dimension of the unfilled SFC will be $40 \times 50 \mathrm{~cm}$, the length of the SFC will not have a special role in the process of dewatering. The maximum length of the SFC is determined by the convenience of its further loading and transportation. The most optimal location of the injection nozzle is at the top of the SFC to ensure the convenience of filling with water slurry. In case of significant length of the PFC (more than $5 \mathrm{~m}$ ) it is reasonable to have 2 or more branch pipes.

\section{References}

1. P.C. Lodi, B.S. Bueno, O.M. Vilar, N.S. Correia, Proc 4th Asian Regional Conf Geosynth, 35 (2008)

2. L.D. Suits, Y.G. Hsuan, Geotextiles and Geomembranes, 21, 111 (2003)

3. M. Tyulenev, Yu. Lesin, E. Tyuleneva, E. Murko, E3S Web of Conf., 15, 02003, (2017)

4. H.J. Kim, T.W. Park, P.R. Dinoy, H.S. Kim, Geosynth Int, 25:5, 507 (2018)

5. E.C. Shin, Y.I. Oh, Geosynth Int, 10:6, 134 (2003)

6. D. Leshchinsky, O. Leshchinsky, H.I. Ling, P.A. Gilbert, J Geotech Eng, 122:8, 682 (1996)

7. H.J. Kim, M.S. Won, J.C. Jamin, J.H. Joo, Geotextiles and Geomembranes, 44:2, 209 (2016)

8. S. Markov, M. Tyulenev, O. Litvin, E. Tyuleneva, E3S Web of Conf., 15, 01011, (2017)

9. K. Terzaghi, Theoretical Soil Mechanics. John Wiley \& Sons, New York (1943)

10. R. H. Plaut, S. Suherman, Acta Mech, 129:3, 207 (1998) 
11. M. A. Tyulenev, S. O. Markov, M. A. Gasanov, S. A. Zhironkin, Geotech Geol Eng, 36:5, 2789 (2018)

12. K. Liao, S. K. Bhatia, Proc NAGS 2005/GRI-19 Cooperat Conf, 1 (2005)

13. M. Mikasa, The Consolidation of Soft Clay - A New Consolidation Theory and its Application (Kajima Institution Publishing Co., Ltd., Tokyo (1963)

14. M. Mikasa, N. Takada, Proc Symp Sedimentation Consolidation Models - Prediction and Validation, 121 (1984)

15. M. Tyulenev, A. Khoreshok, E. Garina, O. Litvin, Y. Litvin, E. Maliukhina, IOP Conference Series: Earth and Environmental Science, 50:1, 012035, (2017)

16. M.M. Khachan, S.K. Batia, Geotextiles and Geomembranes, 45:4, 280 (2017)

17. T.S. Ingold, The Geotextiles and Geomembranes Manual. Elsevier Advanced Technology, UK (1994)

18. V.A. Kalashnikov, A.V. Gorbachev, J Mining Geotech Eng, 3, 56 (2018)

19. N.W. M. John, Geotextiles. Blackie, London (1987)

20. R.W. Thomas, K.L. Verschoor, Geotech Fabrics Rept, 6:3, 24 (1988)

21. Y.H. Halse, J. Wiertz, J.M. Rigo, Chemical identification methods used to characterize polymeric geomembranes. Chapter 15. Geomembranes Identification and Performance Testing Chapman \& Hall, London (1991)

22. R.E. Landreth, Chemical resistance evaluation of geosynthetics used in the waste management applications. Geosynthetics Testing for Waste Containment Applications. Special Technical Publication STP 1081, ASTM, Philadelphia (1990)

23. P.R. Rankilor, Membranes in Ground Engineering. John Wiley \& Sons, Chichester, England (1981)

24. A. Bouazza, G. Heerten Geosynthetic applications - sustainability aspects. Chapter 18, Handbook of Geosynthetic Engineering. ICE Publishing, London (2012)

25. R.D. Espinoza, Geotextiles and Geomembranes, 13:5, 281 (1994)

26. J.E. Fluet, Proc Symp Geosynth Soil Improv, 1 (1988)

27. J.P. Giroud, Geotech Fabrics Rept, 10:5, 6 (1992)

28. S. Markov, V. Martyanov, E. Preis, A. Abay, E3S Web of Conf., 21, 01021 (2017)

29. W. Bialy, W. Grebski, G. Galecki, W. Kaniak, Acta Montanistica Slovaca, 25:2, 139, (2020)

30. A.L. Rutkovsky, A.B. Lolaev, E.I. Meshkov, M.A. Kovaleva, Sustainable development of mountain territories, 10:2, 253, (2018)

31. A. Strelnikov, S. Markov, L. Rattmann, D. Weber, E3S Web of Conf., 41, 01003, (2018)

32. O.O. Garshin, Z.A. Startseva, J Mining Geotech Eng, 2, 33 (2019)

33. Yu. Lesin, V. Gogolin, E. Murko, S. Markov, Ju. Kretschmann, E3S Web of Conf., 41, 01039 (2018)

34. J. Sitko, Z. Farhad, Acta Montanistica Slovaca, 25:3, 350 (2020) 